\title{
Performance of double chamber microbial fuel cell: effect of waste water, electrode thickness and distance
}

\author{
Aziah Khamis, Nurdiana Nordin, Mohd Hafiszi Mokhtar \\ Faculty of Electrical Engineering, Universiti Teknikal Malaysia Melaka, Malaysia
}

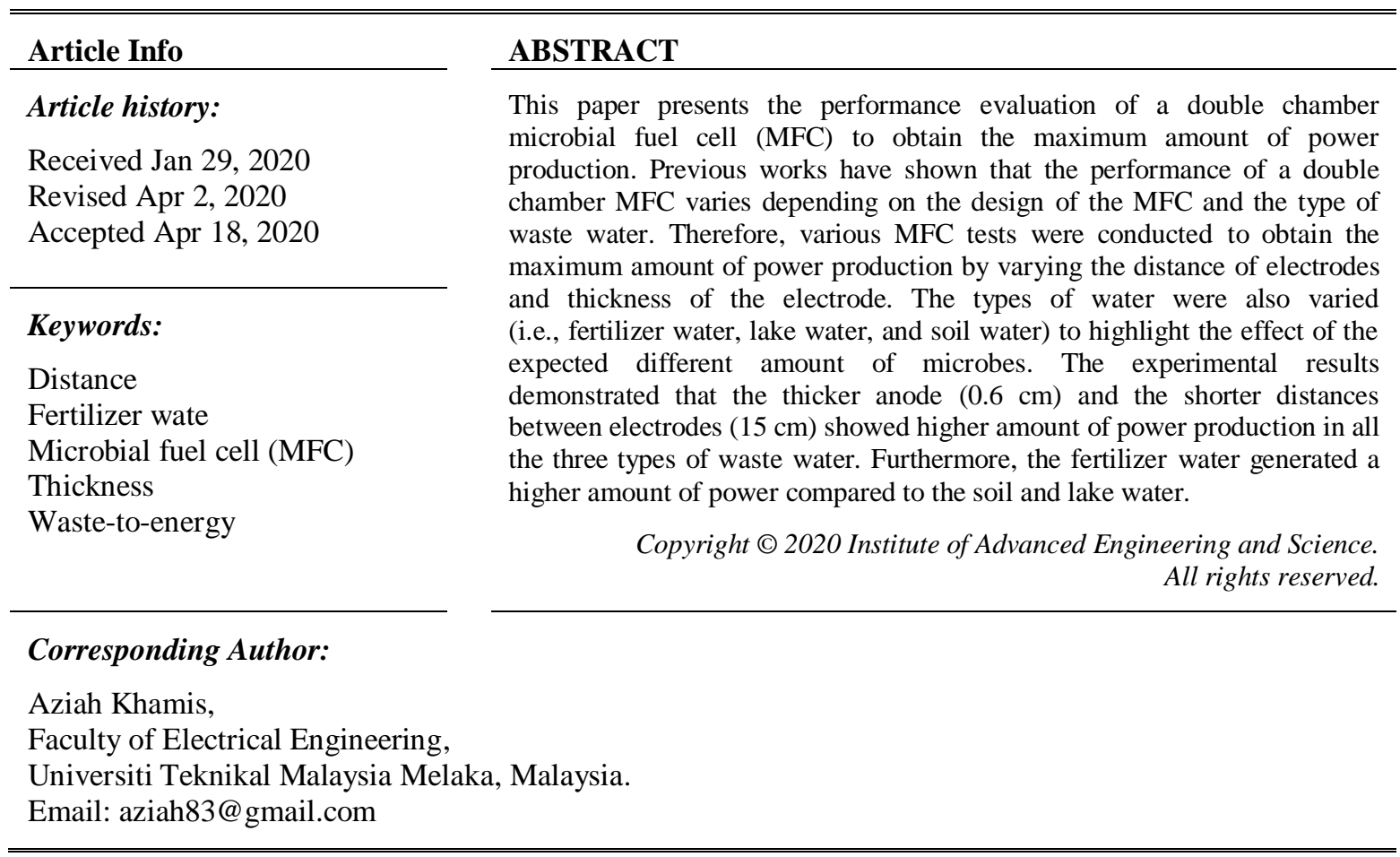

\section{INTRODUCTION}

Recently, waste water energy harvesting called Microbial Fuel Cell (MFC) has become a common subject due to a substantial increase in the population of waste water [1,2]. MFC is a type of fuel cell that uses microorganism that lives inside the waste water and certain electrochemical reaction to generate electricity [3]. MFC can continue to produce the electricity as long as the microorganism is alive and active. With the continuous supply of food, the microorganism can continue to live and reproduce. Besides, MFC does not produce harmful waste, thus it is environment-friendly [4-9].

In MFC, the microorganism is a structure in biofilm and lives in close contact with the electrode. MFC is specifically a device that uses bacteria to turn the energy stored in chemical bonds into electrical current that can be used without the need for combustion [3]. Electricity is produced via an electron movement from decaying certain material in the waste water [10-15]. There are a couple of factors that influences the waste water energy harvesting using MFC. An adaptation or change of the microbial community will influence the biofilm structure and properties. In a suitable environment, the microorganism can be active and reproduce hence increase the voltage output by the MFC [16]. The different types of waste water can also affect the reproduction of microorganism. For instance, marine sediment, soil waste water, freshwater sediment and activated sludge are all rich sources for these microorganisms that are able to generate the electricity [13-16]. Although the energy produced is not yet practical on a scale larger than simple demonstrations, a thorough understanding of how bioenergy works and how it could one day be integrated into our energy generation systems is helpful.

Various techniques were developed to improve the efficiency of MFC to harness electricity. Many of those required further work to ensure practical implementation. For instance, the different electrode distance and surface area were proposed in [10]. However, further research should be done, as the experiment 
is expensive due to the usage of many electrodes at the anode and the need for a bigger space to fit three electrodes. Interestingly, Shaoan Cheng et al. (2006) showed that a wet-proofed carbon cloth with diffusion layer (DL) can increased performance of MFC compared to the structure of cathode without DL [17]. While in another study [18], the different type of waste water was utilized to increase the performance of MFC based on the amount of microbes.

Furthermore, the performance of MFCs can also be improved by improving reactor design, using new electrode materials and enhancing microbial community enrichment, where the MFC performance was discussed steadily increasing in [19, 20]. Meanwhile, in 2013 [21] evaluated the low cost MFC considering the organic matter removal, coulombic efficiencies, and current and power density. In contrast to [22, 23], Booki Min et al (2005) [24] argues that the power produced more in single-chambered compared to double chambered. [24] found that the maximum power density using a two-chambered MFC was six times greater than single-chambered. However, the limitation of this MFC is due to the high concentration of ammonia in the waste water [25]. Several obstacles were needed to be addressed such as the need to implement sustainable cathodes, the fate of certain organics in sewage and the elimination of residual nutrients.

Based on the previous works, it is clear that the design of the MFC and the amount of microbes present in the waste water have been influential to the power output of the MFC. Motivated by the promising results in our previous works [26], as well as the six times greater maximum power density presented in [24], this paper continues our line of research and devises an improvement in the design of the MFC using double chamber technique. This study attempts to evaluate the performance of a double chamber MFC by manipulating the waste water, electrode thickness and the distance in order to attain the maximum power output. The results of this research will provide insight to the specific design of electrodes in the double chamber MFC and the corresponding waste water that produces the maximum power output.

\section{RESEARCH METHOD}

This section describes the overview of numeric tools and procedures that have been applied in the implementation of MFC for generating electricity. The main focuses for MFC in this project are the different type of waste water used in the anaerobic chamber, the distance of electrode and thickness of electrode in both anaerobic and aerobic chamber. By manipulating all the variables, the best condition to enhance the performance of MFC can be attained. The result of these experiments then evaluated and compared.

As shown in Figure 1, MFC consists of two chambers, which are the aerobic chamber and the anaerobic chamber. The aerobic chamber is continuously supplied with oxygen. Meanwhile, the anaerobic chamber is sealed to avoid oxygen. The anode electrode is placed at the anaerobic chamber which contains waste water, while the cathode electrode is placed at the aerobic chamber that contains distilled water. The bacteria or microbes inside the waste water will be attached to the anode electrode. These bacteria slowly decomposed into the organic matter: free-electron, hydrogen, and carbon dioxide. As shown in (1) summarizes the general reaction in the anode chamber [10].

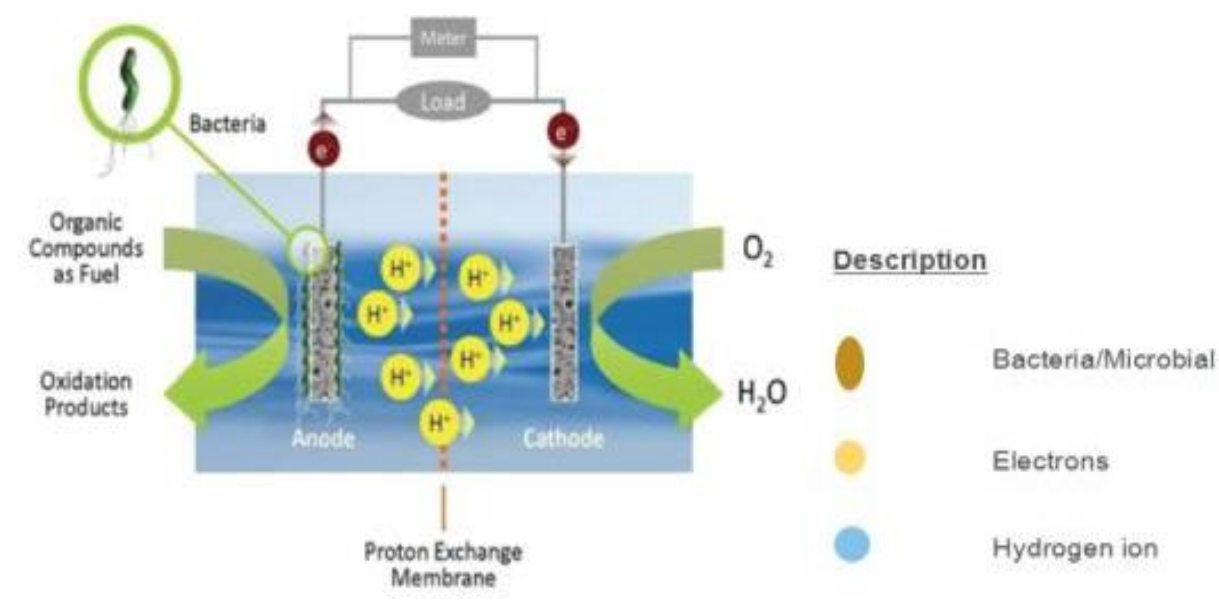

Figure 1. Concept of microbial fuel cell

Biodegradable Organic $=\mathrm{CO}_{2}+\mathrm{H}^{+}+\mathrm{e}$ 
The electrons produced by the bacteria's decomposition will be attracted to the anode electrode, sometimes supported by a mediator molecule. They will then flow into the cathode from the anode, through a wire. These electrons need to be harvested to generate electricity. For the hydrogen ions, they will flow through the exchange membrane to the aerobic chamber. This process is driven by the electrochemical gradient resulting from the high concentration of the hydrogen ions near the anode. For the hydrogen ions, it flows into the aerobic chamber via the exchange membrane. The electrochemical gradient that results from the high concentration of hydrogen ions near the anode drives this process. The cathode electrons combine pure $\mathrm{H}_{2} \mathrm{O}$ or pure water with dissolved oxygen in the aerobic chamber and hydrogen ions. As shown in (2) summarizes the general reaction in the cathode chamber.

$$
2 \mathrm{O}_{2}+8 \mathrm{H}^{+}+8 \mathrm{e}=4 \mathrm{H}_{2} \mathrm{O}
$$

\subsection{General material and apparatus}

This section describes the overview of numeric tools, materials, and procedure that has been applied in generating electricity from waste water using the MFC double chamber. Several experiments were conducted and evaluated to find the best and suitable ways to generate electricity using MFC double chamber. The apparatus used in the experiment is shown in Table 1. The experiment was set up with a double chamber, where each chamber act as anode and cathode, respectively. These chambers then connected by the pipe as the chemical exchange membrane also known as a salt bridge used for the hydrogen ion to flow through. The anode metal is connected to the cathode metal by a crocodile clip with wire for the electrons to flow through. Each chamber is filled with the $500 \mathrm{ml}$ volume of distilled water and waste water.

Table 1. Apparatus used in experiment

\begin{tabular}{cc}
\hline Number & Apparatus \\
\hline 2 & Container \\
$20 \mathrm{~mm}($ diameter $)$ & PVC pipe \\
3 & Tank Connector \\
4 & Crocodile clip with wire \\
2 & Copper electrode \\
$500 \mathrm{ml}$ & Distilled water \\
$500 \mathrm{ml}$ & Each type of waste water \\
$200 \mathrm{gram}$ & Gelatine \\
50 gram & Salt \\
\hline
\end{tabular}

\subsection{Performance factor}

\subsubsection{Electrolyte}

These apparatuses are being constructed based on several steps to create a general set up for the different types of waste water test. These apparatuses are being constructed based on several steps to create a general set up for the different types of waste water test. The gelatine was heated over the stovetop and salt is dissolved to make the proton exchange membrane (PEM) or salt bridge. The boiled gelatine and salt were then poured and mixed into the holes of the container sides. The culture media was obtained from few sources such as the fertilizer water, soil water, and lake water. The reason such places were chosen is because it might contains a lot of anaerobic bacteria. Copper plate with an original thickness of $0.2 \mathrm{~cm}$ was folded a few times and connected to a large paper clip to make the electrodes. Thus, the entire electrode surface area is $36 \mathrm{~cm}^{2}$. The strips end with the copper wire and is connected to both electrodes. The copper wire were inserted on the lids into drilled holes. The reactor part, which is an aerobic chamber and anaerobic chamber were assembled and both of the chambers were connected by the PEM or salt bridge. These MFC were operated for 40 days. The resistance of $100 \mathrm{ohms}$ was connected between the cathode and anode with a crocodile clip. The data from MFC were collected by measuring the voltage across the resistor and current, power and power density was calculated for the three different types of waste water.

\subsubsection{Electrode thickness}

To evaluate the effect of thickness of electrode to the generation of electricity production. Two thickness of the electrode is tested as shown in Figure 2, where the thickness of the electrode is $0.2 \mathrm{~cm}$ and $0.6 \mathrm{~cm}$, respectively. The implementation steps to assemble the electrode thickness can be illustrated in Figure 3. Note that the general apparatus and the analysis result presented in Figure 3 is the same process illustrated in the aforementioned test. 


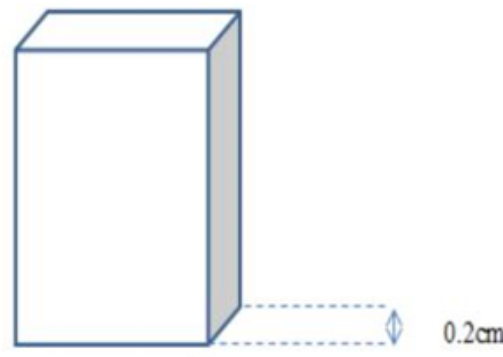

(a)

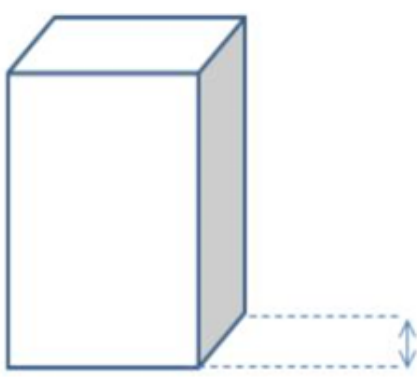

(b)

Figure 2. Thickness of Anode based on: (a) $0.2 \mathrm{~cm}$ and (b) $0.6 \mathrm{~cm}$

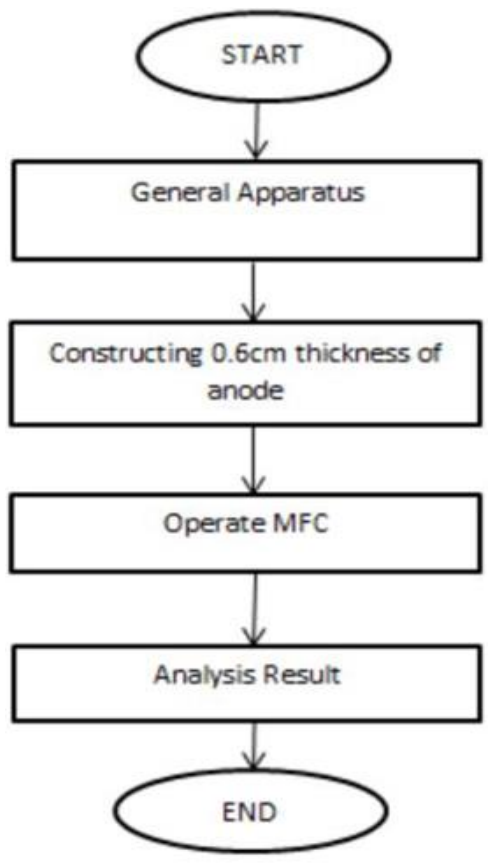

Figure 3. Implementation step of electrode thickness test

\subsubsection{Electrode distance}

To evaluate the effect of electrode distance in MFC, two different distance is tested, which is $15 \mathrm{~cm}$ and $25 \mathrm{~cm}$. The distance of the electrode is measured by setting the distance between anode in the anaerobic chamber and cathode in the aerobic chamber as illustrated in Figure 4. The overall implementation step of the electrode distance test illustrated in Figure 5. Note that the general apparatus and the analysis result presented in Figure 5 is the same process illustrated in the aforementioned test.

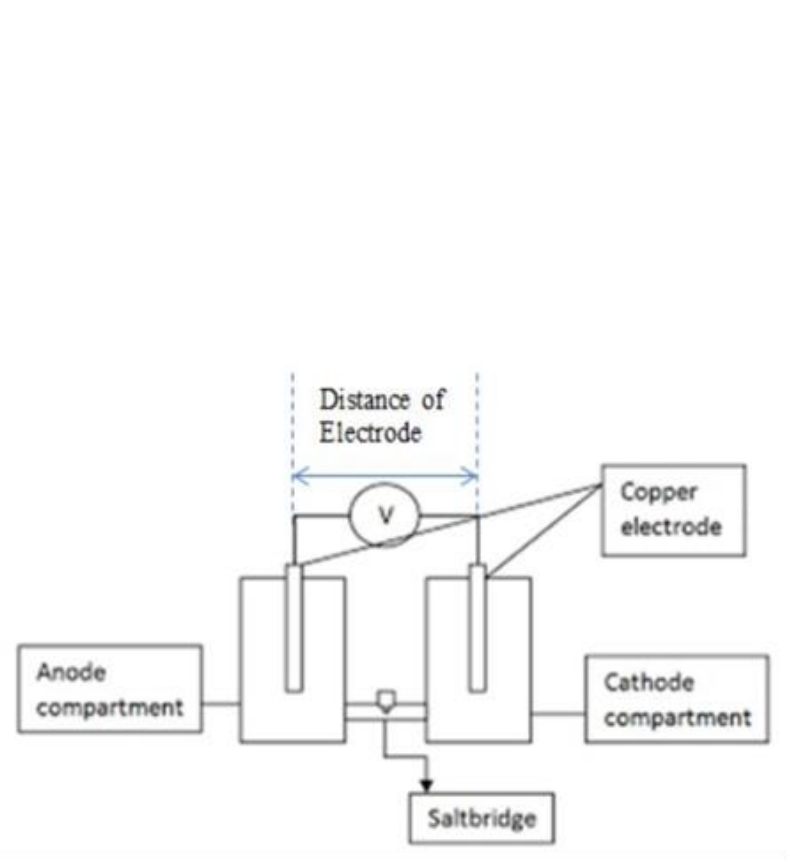

Figure 4. The measurement for electrode distance

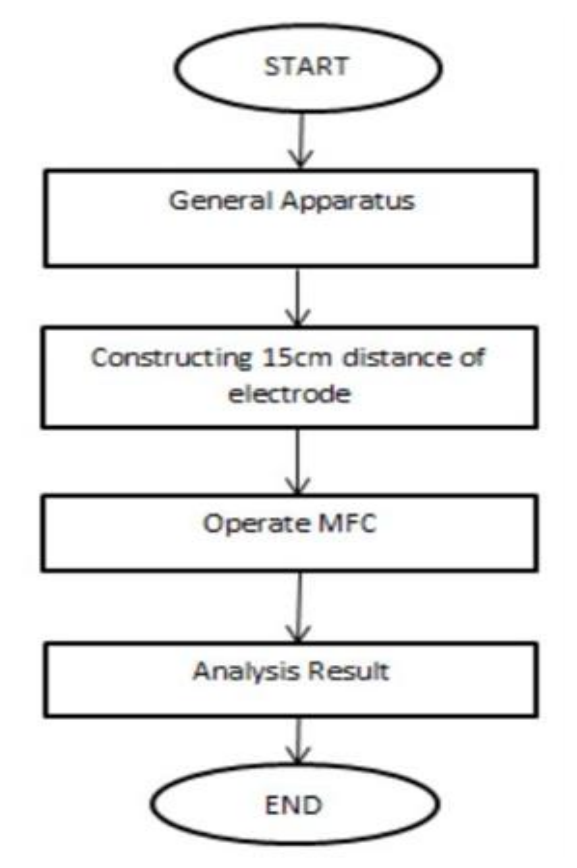

Figure 5. Implementation step of electrode distance test 


\subsection{Performance variable}

The performance of the double chamber MFC is evaluated based on the amount of voltage density, current density and power density produced. Firstly, the experiments were done simultaneously with the different types of waste water, where the measurement of voltage and current are recorded every 24 hours within 40 days using a multimeter. The resistor connected to the MFC is $100 \mathrm{ohms}$. Next, the voltage density, current density, and power density are calculated. Finally, the data is analyzed by finding the relationship between power density and the current density based on the voltage generations. The same formulation of power and current density were utilized from our previous work [26], which can be formulated as follows:

$$
\begin{aligned}
& P_{D}=\frac{\text { Pout }}{A}=\frac{\text { Vout I out }}{A} \\
& I_{D}=\frac{\text { Iout }}{A}
\end{aligned}
$$

where power density $\left(\mathrm{P}_{\mathrm{D}}\right)$ represents the power density in watt $/ \mathrm{m}^{2}, \mathrm{P}_{\text {out }}$ represent the power produce by the MFC in watt (W) and A represents the electrode surface area in $\mathrm{m}^{2} . \mathrm{V}_{\text {out }}$ represent the voltage output in volt $(V), I_{\text {out }}$ represents the current output in ampere $(A)$, while $I_{D}$ represents the current density in ampere $/ \mathrm{m}^{2}$.

The measurement for the total surface area of the electrode is calculated by adding the surface area for the front side and the backside of the copper plate. For this study, the height of the electrode used is 4.5 $\mathrm{cm}$ and the length is $4 \mathrm{~cm}$ as illustrated in Figure 6. Thus, the total surface area for the copper plate is $36 \mathrm{~cm}^{2}$.

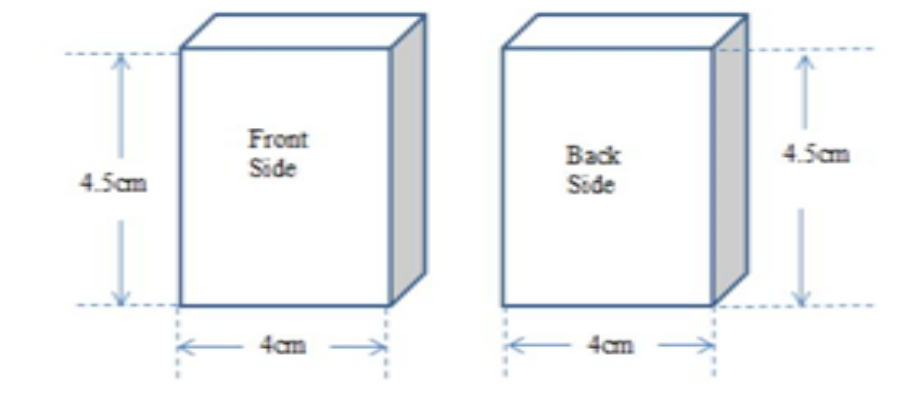

Figure 6. Dimension of copper plate

\section{RESULT AND DISCUSSIONS}

\subsection{Electrolyte factor}

Figure 7 presents the comparative performance of the power density for soil water, lake water, and fertilizer water which represented as a blue shape, green shape and magenta shape, respectively. From the observation, it can be seen that the power density of the fertilizer water is higher than lake water and soil water. Therefore, from the different types of waste water tested, the fertilizer water is the most effective type of waste water in producing electricity using MFC double chamber compared to the soil water and the lake water.

Table 2 presents the maximum data of the voltage, current, power and power density produced with the usage of soil water, lake water and fertilize water, respectively. From the table, the higher rate of output is obtained when the MFC uses fertilizer water as its waste water. However, after each different type of water reaches the maximum performance or maximum voltage, the graph start to slightly decrease. This is due to the fewer amounts of microbes left after the decomposition of microbes takes place in the anaerobic chamber. Fewer electrons are produced after the bacteria start to feed each other, thus the performance of MFC slightly decrease until 40 days. The inference that can be made from the 40 days of the experiment is that, a different type of waste water affects the efficiency of the MFC to generate energy. This is due to the number of microbes contaminated in the waste water. From this comparison, it is evident that the fertilize water has more organic composites that can be decomposed by microbe and bacteria than other types of waste water.

Table 2. The maximum voltage, current, power and power density produced for 3 different type of waste water

\begin{tabular}{ccccc}
\hline Waste Water & $\mathrm{P}(\mathrm{mW})$ & $\mathrm{V}(\mathrm{V})$ & $\mathrm{I}(\mathrm{mA})$ & $\mathrm{P}_{\mathrm{D}}\left(\mathrm{mW} / \mathrm{cm}^{2}\right)$ \\
\hline Soil & 14.400 & 1.200 & 12.000 & 0.400 \\
Lake & 20.449 & 1.4300 & 14.300 & 0.568 \\
Fertilizer & 28.561 & 1.690 & 16.900 & 0.793 \\
\hline
\end{tabular}

Performance of double chamber microbial fuel cell: effect of waste water, electrode... (Aziah Khamis) 


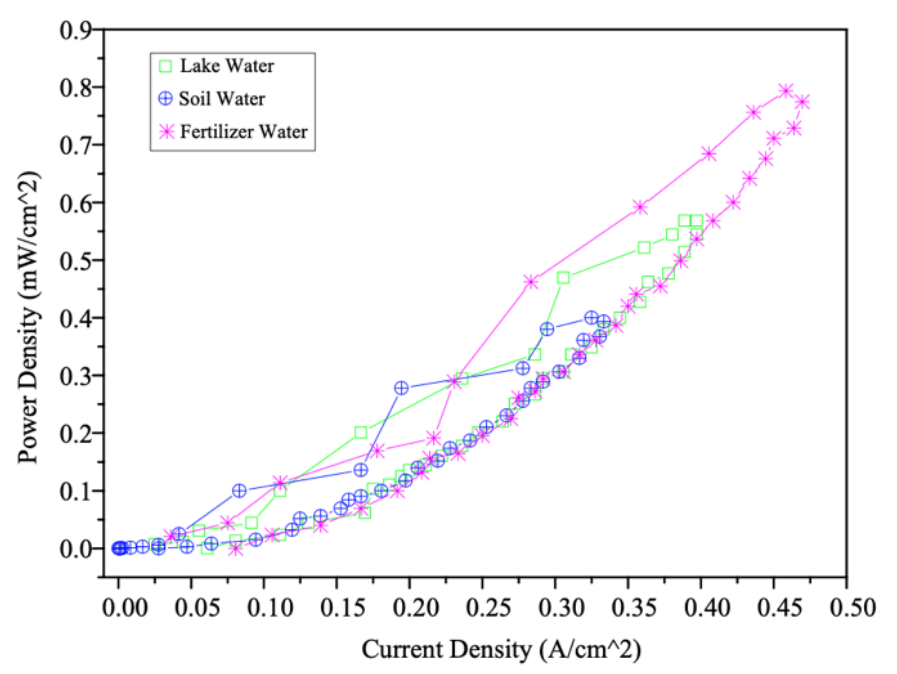

Figure 7. Performance of different waste water test based on power density and current density

\subsection{Electrode thickness factor}

Figure 8 plots the comparison performance of the power density for soil water, lake water, and fertilizer water, which represented as the blue shape, the green shape the magenta shape, respectively. It can be seen that the power density of the fertilizer water is higher than lake water and soil water. Moreover, the graphs from Figure 8 increase rapidly when the thickness of anode is increase by $0.6 \mathrm{~cm}$. Therefore, the increase in the thickness of anode will further increase the performance of generating electricity of the MFC.

To evaluate the effect of electrode thickness in generating the electricity, the comparative study between the different thickness of electrode was tested. Table 3 shows the comparative study for electrode thickness test in term of power, voltage, current and power density. From the observation, it can be seen that the improvement of power density can be observed when the electrode thickness is being used. For instance, $13.6 \%$ of power density is increased for the fertilizer water when it used a $0.6 \mathrm{~cm}$ electrode thickness in comparison to $0.2 \mathrm{~cm}$ electrode thickness. Thus, it proves that the use of a thicker anode is an important factor in power production not only because of the increment in the surface area for bacterial growth but also because the thick anode could provide an environment whereby the bacteria inside of the anode can remain in a highly anoxic environment compared to bacteria on the outside of the electrode.

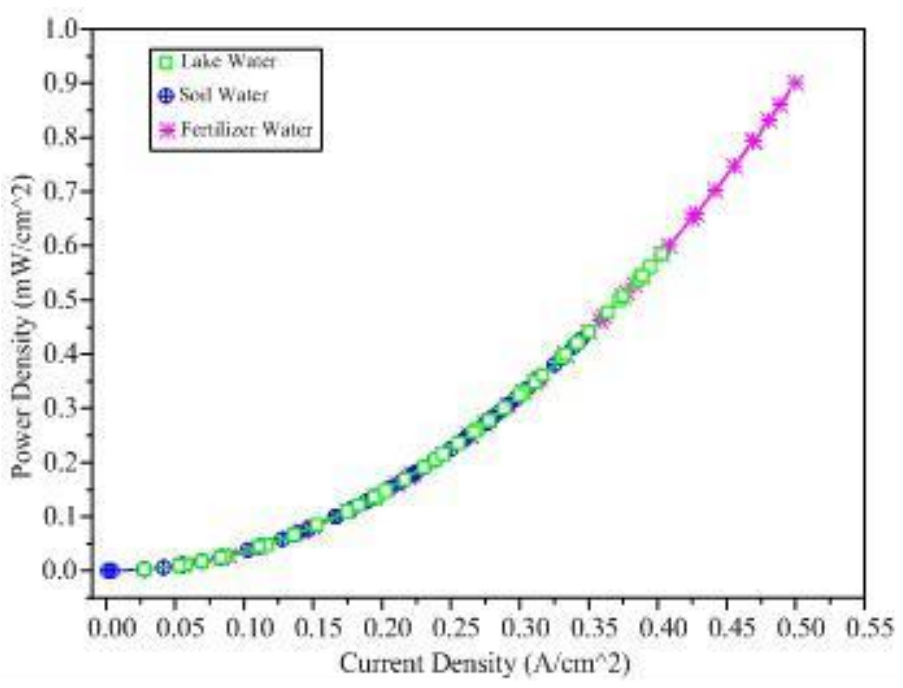

Figure 8. Performance of electrode thickness: $0.6 \mathrm{~cm}$ based on power density and current density 
Table 3. The comparison of maximum performance of MFC based on electrode thickness test

\begin{tabular}{cccccc}
\hline Waste Water & Electrode Thickness $(\mathrm{cm})$ & $\mathrm{P}(\mathrm{mW})$ & $\mathrm{V}(\mathrm{V})$ & $\mathrm{I}(\mathrm{mA})$ & $\mathrm{P}_{\mathrm{D}}\left(\mathrm{mW} / \mathrm{cm}^{2}\right)$ \\
\hline Soil & & 14.400 & 1.200 & 12.000 & 0.400 \\
Lake & 0.2 & 20.449 & 1.4300 & 14.300 & 0.568 \\
Fertilizer & & 28.561 & 1.690 & 16.900 & 0.793 \\
& & & & & \\
Soil & \multirow{2}{*}{0.6} & 15.380 & 1.240 & 12.400 & 0.427 \\
Lake & & 21.030 & 1.450 & 14.500 & 0.584 \\
Fertilizer & & 32.400 & 1.800 & 18.000 & 0.900 \\
\hline
\end{tabular}

\subsection{Electrode distance factor}

Figure 9 illustrates the change in power density for soil water, lake water, and fertilizer water when the electrode distance is decreased to $15 \mathrm{~cm}$. The observation reveals that the fertilizer water outperformed lake and soil water with the highest power density value as depicted in Figure 9. Therefore, the finding proves that the fertilizer water is the most effective type of waste water in producing electricity compared to soil and lake water.

To further evaluate the effect of electrode distance in generating the electricity with MFC double chamber, the comparative performance between the electrode distances is tested. Table 4 illustrates the comparative study in term of power, voltage, current and power density. From the table, it can be observed that the performance of MFC when the electrodes distance is $15 \mathrm{~cm}$ outperformed the performance when the electrode distance is at $25 \mathrm{~cm}$. For instance, there was a $26.36 \%$ increment of power density for the fertilizer water when the electrode distance was at $15 \mathrm{~cm}$ compared to when the electrode distance was at $25 \mathrm{~cm}$. Thus, it proves that the small distance of the electrode may lead to better transfer of electrons and protons from the bacteria to the anode or from the anode to the cathode due to the smaller ohm resistance. When a gap is present between the anode and the proton exchange membrane (salt bridge), protons (hydrogen ions) that are generated by the bacteria cannot move directly to the salt bridge. Thus, the hydrogen ions will be carried by the waste water in the anode chamber.

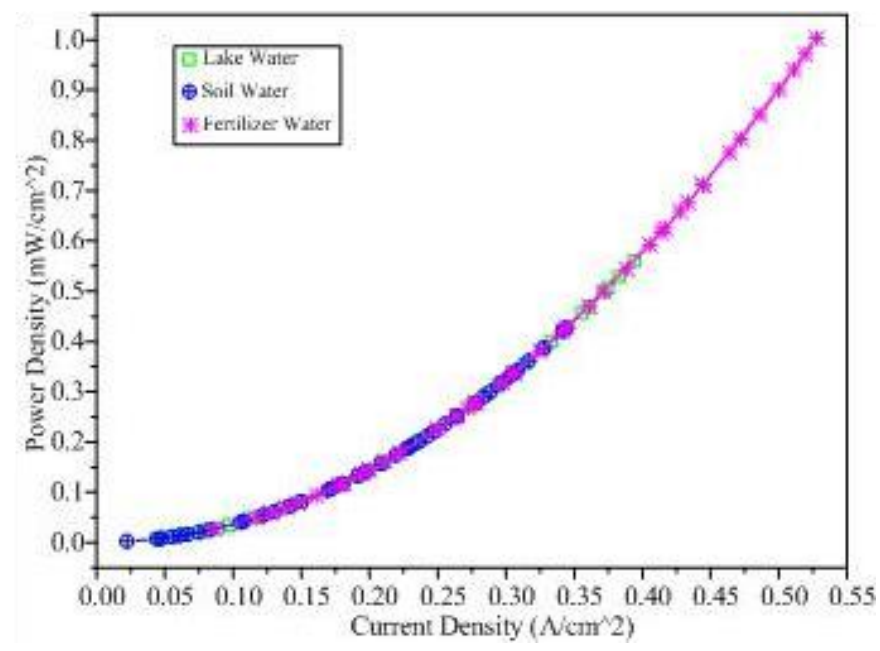

Figure 9. Performance of electrode distance: $15 \mathrm{~cm}$ based on power density and current density

Table 4. The comparison of maximum performance of MFC based on electrode distance test

\begin{tabular}{cccccc}
\hline Waste Water & Electrode Distance $(\mathrm{cm})$ & $\mathrm{P}(\mathrm{mW})$ & $\mathrm{V}(V)$ & $\mathrm{I}(\mathrm{mA})$ & $\mathrm{P}_{\mathrm{D}}\left(\mathrm{mW} / \mathrm{cm}^{2}\right)$ \\
\hline Soil & & 15.380 & 1.240 & 12.400 & 0.427 \\
Lake & \multirow{2}{*}{5} & 21.030 & 1.450 & 14.500 & 0.584 \\
Fertilizer & & 32.400 & 1.800 & 18.000 & 0.900 \\
& & & & & \\
Soil & \multirow{2}{*}{25} & 14.400 & 1.200 & 12.000 & 0.400 \\
Lake & & 20.449 & 1.4300 & 14.300 & 0.568 \\
Fertilizer & & 28.561 & 1.690 & 16.900 & 0.793 \\
\hline
\end{tabular}

\section{CONCLUSION}

This paper presents the performance of a double chamber MFC by varying the type of electrolytes, the electrode thickness and electrode distance. The results have shown that in order to produce a higher

Performance of double chamber microbial fuel cell: effect of waste water, electrode... (Aziah Khamis) 
amount of electricity, the electrodes should be built thicker and with a shorter distance between each other. The double chamber MFC tested also produced the highest electricity when it was run using fertilizer water in comparison to soil water and lake water. This showed that the rich content of fertilizer water is influential to the performance of the double chamber MFC.

\section{REFERENCES}

[1] Hernndez-Fernndez, F. J., et al., "Recent Progress and Perspectives In Microbial Fuel Cells for Bioenergy Generation and Wastewater Treatment," Fuel Processing Technology, vol. 138, pp. 284-297, 2015.

[2] Fan, Y., Hu, H. and Liu, H., "Sustainable Power Generation in Microbial Fuel Cells Using Bicarbonate Buffer and Proton Transfer Mechanisms," Environmental Science and Technology, vol. 41, no. 23, pp. 8154-8158, 2007.

[3] Kim, Byung Hong, et al., "Enrichment of Microbial Community Generating Electricity Using A Fuel-Cell-Type Electrochemical Cell," Applied Microbiology and Biotechnology, vol. 63, no. 6, pp. 672-681, 2004.

[4] Min, B. and Logan, B.E., "Continuous Electricity Generation from Domestic Wastewater and Organic Substrates in A Flat Plate Microbial Fuel Cell," Environmental Science and Technology, vol. 38, no. 21, pp. 5809-5814, 2004.

[5] Mukherjee, M.K. and Thamotharan, P.C., "Performance and Emission Test of Several Blends of Waste Plastic Oil with Diesel and Ethanol on Four Stroke Twin Cylinder Diesel Engine," IOSR Journal of Mechanical and Civil Engineering (IOSR-JMCE), vol. 11, no. 2, pp. 47-51, 2014.

[6] Chinwan, D. and Pant, S., "Waste To Energy in India and its Management," Journal of Basic and Applied Engineering Research, vol. 1, no. 10, pp. 89-94, 2014.

[7] Ramly, Ruwaida, Aznida Abu Bakar Sajak, and Muhaira Rashid, "IoT Recycle Management System to Support Green City Initiatives," Indonesian Journal of Electrical Engineering and Computer Science (IJEECS), vol. 15, no. 2, pp. 1037-1045, 2019.

[8] Gaya, Muhammad Sani, et al., "Estimation of Water Quality Index using Artificial Intelligence Approaches and Multilinear Regression," IAES International Journal of Artificial Intelligence (IJ-AI), vol. 9, no. 1, pp. 126-134, 2020.

[9] Gaya, M S, et al., "Estimation of Turbidity in Water Treatment Plant using Hammerstein-Wiener and Neural Network Technique," Indonesian Journal of Electrical Engineering and Computer Science (IJEECS, vol. 5, no. 3, pp 666-672, 2017.

[10] Ghangrekar, M.M. and Shinde, V.B., "Performance of Membrane-Less Microbial Fuel Cell Treating Wastewater and Effect of Electrode Distance and Area On Electricity Production," Bioresource Technology, vol. 98, no. 15, pp. 2879-2885, 2007.

[11] Jiansheng H, Ping Y, Yong G, Zhang K, "Electricity Generation during Wastewater Treatment: An Approach using AFB-MFC for alcohol Distillery Wastewater," Desalination, vol. 276, no. 1-3, pp. 373-378, 2011.

[12] Anand Parkash, "Design and Fabrication of a Double Chamber Microbial Fuel Cell for Voltage Generation from Biowaste," Journal of Bioprocessing and Biotechnique, vol. 5, no. 8, pp. 1-4, 2015.

[13] Do, M. H., et al., "Challenges in The Application of Microbial Fuel Cells to Wastewater Treatment and Energy Production: A Mini Review," Science of the Total Environment, vol. 639, pp. 910-920, 2018.

[14] Ditzig J, Liu H, Logan BE., "Production of Hydrogen from Domestic Wastewater using A Bioelectrochemically Assisted Microbial Reactor (BEAMR)," International Journal of Hydrogen Energy, vol. 32, pp. 2296-2304, 2007.

[15] Logan BE., "Scaling Up Microbial Fuel Cells and Other Bioelectrochemical Systems," Applied Microbiology and Biotechnology, vol. 85, pp. 1665-1671, 2010.

[16] Mcaveney, P., Pedersen, B. and Wong, J.C., "Microbial Fuel Cell Using Inexpensive Materials.” 2012.

[17] Cheng, S., Liu, H. and Logan, B.E., "Increased Performance of Single-Chamber Microbial Fuel Cells Using an Improved Cathode Structure," Electrochemistry Communications, vol. 8, no. 3, pp. 489-494, 2006.

[18] Aelterman, Peter, et al., "Microbial Fuel Cells for waste water Treatment," Water Science and Technology, vol. 54, no. 8, pp. 9-15, 2006.

[19] Aelterman, Peter, et al., "Loading Rate and External Resistance Control the Electricity Generation of Microbial Fuel Cells with Different Three-Dimensional Anodes," Bioresource technology, vol.99, no. 18, pp. 8895-8902, 2008.

[20] Pham, The Hai, Peter Aelterman, and Willy Verstraete, "Bioanode Performance in Bioelectrochemical Systems: Recent Improvements and Prospects," Trends in biotechnology, vol. 27, no. 3, pp. 168-178, 2009.

[21] Buitrn, Germn, and Carlos Cervantes-Astorga, "Performance Evaluation of A Low-cost Microbial Fuel Cell using Municipal Wastewater," Water, Air, and Soil Pollution, vol. 224, no. 3, pp. 1470-1478, 2013.

[22] Liu, Hong, and Bruce E. Logan, "Electricity Generation using An Air-cathode Single Chamber Microbial Fuel Cell in The Presence and Absence of a Proton Exchange Membrane," Environmental Science and Technology, vol. 38, no. 14, pp. 4040-4046, 2004.

[23] Oh, Sangeun, Booki Min, and Bruce E. Logan, "Cathode Performance as A Factor in Electricity Generation in Microbial Fuel Cells," Environmental Science and Technology, vol. 38, no. 18, pp. 4900-4904, 2004.

[24] Min, Booki, et al., "Electricity Generation from Swine Wastewater using Microbial Fuel Cells," Water Research, vol. 39, vol. 20, pp. 4961-4968, 2005.

[25] Rittmann, Bruce E., and Perry L. McCarty., "Environmental Biotechnology: Principles and Applications," Tata McGraw-Hill Education, 2012.

[26] Aziah Khamis, et al., "Comparison Study of The Voltage Generation in Microbial Fuel Cell: Chambers Based on Different Type of Wastewater Test," Symposium Proceeding on Electrical, Mechatronics and Applied Science 2018(Sema2018) pp. 95-96, 2018. 